\title{
Awareness and Metacognition
}

\section{Diego Fernandez-Duque, ${ }^{*}$ Jodie A. Baird, $\dagger$ and Michael I. Posner $\uparrow^{1}$}

\begin{abstract}
*Rotman Research Institute, Baycrest Center for Geriatric Care, 3560 Bathurst Street, Toronto, Ontario, Canada M6A IE6; †Institute of Child Study, University of Toronto, 45 Walmer Road, Toronto, Ontario, Canada M5R 2X2; and $\$$ Sackler Institute, Department of Psychiatry, Weill Medical College of Cornell University, Box 140, 1300 York Avenue, New York, New York 10021 E-mail: diego@rotman-baycrest.on.ca,jbaird@oise.utoronto.ca,mip2003@mail.med.cornell.edu
\end{abstract}

Kentridge and Heywood (this issue) extend the concept of metacognition to include unconscious processes. We acknowledge the possible contribution of unconscious processes, but favor a central role of awareness in metacognition. We welcome Shimamura's (this issue) extension of the concept of metacognitive regulation to include aspects of working memory, and its relation to executive attention. ๑) 2000 Academic Press

Our central thesis, shared by both reviewers, is that research on metacognition can benefit from a cognitive neuroscience perspective that examines metacognitive regulation in terms of executive control processes. As Shimamura (this issue) points out, research on executive control has successfully decomposed the concept of executive function into specific mental operations, and imaging techniques are starting to identify the corresponding anatomical structures. The reviewers provide evidence in support of this cognitive neuroscience approach to metacognition. Both commentaries extend our concept of metacognitive regulation, although they do so in different directions.

Kentridge and Heywood (this issue) report data from a blindsight patient to argue that metacognitive processes can sometimes be dissociated from awareness. In particular, the claim is that strategy choice is governed by implicit learning (see also Reder \& Schunn, 1996; Schunn \& Dunbar, 1996). The idea that some aspects of executive function and metacognition are sometimes inaccessible to one's insight is consistent with the literature we reviewed in our target article on conflict resolution. However, the existence of implicit executive or metacognitive regulation in a limited set of circumstances, while an interesting phenomenon in itself, does not challenge the idea that awareness is a central component of metacognitive processes.

The importance of awareness for metacognitive regulation is illustrated by recent neuroimaging studies on error detection. After detecting an error, people usually slow down as part of a conscious strategy to minimize the occurrence of future errors. Event-related potentials (ERPs) in speeded tasks reveal an error-related negativity after slips of action (i.e., incorrect executions of a motor program). This error-related

Reply to Commentaries on D. Fernandez-Duque, J. A. Baird, and M. I. Posner (2000). Executive attention and metacognitive regulation. Consciousness and Cognition, 9(2), 288-307. This article is part of a special issue of this journal on Metacognition and Consciousness, with Thomas O. Nelson and Georges Rey as Guest Editors.

${ }^{1}$ To whom reprint requests should be addressed. 
negativity, which most likely originates in the anterior cingulate, correlates in size with the amount of slowing that follows the error. Importantly, for the error-related negativity to occur, and for the error correction to occur, the subject has to be aware of having made an error (Dehaene, Posner, \& Tucker, 1994; Gehring, Gross, Coles, Meyer, \& Donchin, 1993). Thus, it seems that conscious error detection (i.e., metacognitive knowledge) is usually necessary for error correction (i.e., metacognitive regulation).

The role of awareness in metacognition is clearly stated in Shimamura's (this issue) commentary, in which the relation between executive attention and working memory is described. Shimamura identifies four executive processes that we agree are the building blocks of metacognitive control. These are the selection, maintenance, updating, and rerouting of information. Shimamura has nicely extended our analysis to working memory by describing the role of executive control in updating working memory information.

Metacognition has always been a broad concept, difficult to constrain (Brown, Bransford, Ferrara, \& Campione, 1983). This is partly due to the domain generality of metacognitive processes. For example, the same metacognitive rules apply whether one is monitoring his or her performance at playing chess or at reading a text (Flavell, Miller, \& Miller, 1993). Executive attention is also a broad concept, and like metacognition, it seems to be domain general. For example, conflict resolution acts not only on different modalities (e.g., visual, auditory, tactile) but also on different levels of analysis (e.g., perceptual, semantic, action). Executive attention contributes to working memory, and it is in this regard that working memory, defined as the ability to make a conscious report, is closely related to both metacognitive regulation and metacognitive knowledge. However, other aspects of working memory, such as its storage based processes, can be dissociated from executive and metacognitive functions. As research progresses, the taxonomies of working memory, metacognitive, and executive processes should become more clear, as will the interactions and dissociations among them.

\section{REFERENCES}

Brown, A. L., Bransford, J. D., Ferrara, A. L., \& Campione, J. C. (1983). Learning, remembering, and understanding. In J. H. Flavell \& E. M. Markman (Eds.), Handbook of child psychology: Vol. 2. Cognitive development (4th ed., pp. 77-166). New York: Wiley.

Dehaene, S., Posner, M. I., \& Tucker, D. M. (1994). Localization of a neural system for error detection and compensation. Psychological Science, 5, 303-305.

Flavell, J. H., Miller, P. H., \& Miller, S. A. (1993). Cognitive development (3rd ed.). Eaglewood Cliffs, NJ: Prentice Hall.

Gehring, W. J., Gross, B., Coles, M. G. H., Meyer, D. E., \& Donchin, E. (1993). A neural system for error detection and compensation. Psychological Science, 4, 385-390.

Kentridge, R. W., \& Heywood, C. A. (2000). Metacognition and awareness. Consciousness and Cognition, 9, 308-312.

Reder, L. Y., \& Schunn, C. D. (1996). Metacognition does not imply awareness: Strategy choice is governed by implicit learning and memory. In L. Y. Reder (Ed.), Implicit memory and metacognition Mahah, NJ: Erlbaum. 
Schunn, C. D., \& Dunbar, K. (1996). Priming, analogy, and awareness in complex reasoning. Memory and Cognition, 24, 271-284.

Shimamura, A. P. (2000). Toward a cognitive neuroscience of metacognition. Consciousness and Cognition, 9, 313-323. 